THE QUANTITATION OF SULFUR MUSTARD BY-PRODUCTS, SULFUR-CONTAINING HERBICIDES, AND ORGANOPHOSPHONATES IN SOIL AND CONCRETE

Bruce A. Tomkins and Gary A. Sega

Chemical and Analytical Sciences Division, Oak Ridge National Laboratory, Oak Ridge, TN 37831

Sarah J. Macnaughton

Microbial Insights, Inc., 2340 Stock Creek Blvd., Rockford, TN 37853-3044

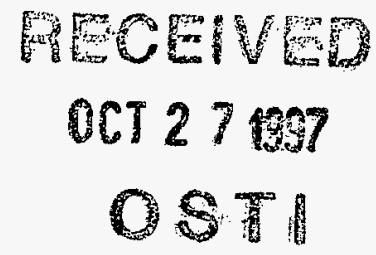

Presented to the

1997 U. S. Army Edgewood Research, Development, and Engineering Center SCIENTIFIC CONFERENCE ON CHEMICAL AND BIOLOGICAL DEFENSE RESEARCH

Edgewood Area Conference Center, Aberdeen Proving Ground, MD November 18-21, 1997

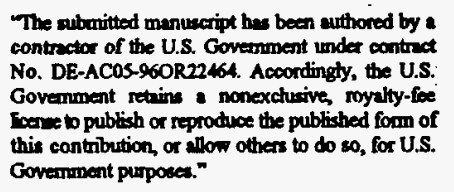

Government purposes." 


\section{DISCLAIMER}

This report was prepared as an account of work sponsored by an agency of the United States Government. Neither the United States Government nor any agency thereof, nor any of their employees, make any warranty, express or implied, or assumes any legal liability or responsibility for the accuracy, completeness, or usefulness of any information, apparatus, product, or process disclosed, or represents that its use would not infringe privately owned rights. Reference herein to any specific commercial product, process, or service by trade name, trademark, manufacturer, or otherwise does not necessarily constitute or imply its endorsement, recommendation, or favoring by the United States Government or any agency thereof. The views and opinions of authors expressed herein do not necessarily state or reflect those of the United States Government or any agency thereof. 


\title{
THE QUANTITATION OF SULFUR MUSTARD BY-PRODUCTS, SULFUR-CONTAINING HERBICIDES, AND ORGANOPHOSPHONATES IN SOIL AND CONCRETE
}

\author{
Bruce A. Tomkins and Gary A. Sega \\ Chemical and Analytical Sciences Division, Oak Ridge National Laboratory, Oak Ridge, TN 37831 \\ Sarah J. Macnaughton \\ Microbial Insights, Inc., 2340 Stock Creek Blvd., Rockford, TN 37853-3044
}

\begin{abstract}
Over the past fifty years, the facilities at Rocky Mountain Arsenal have been used for the manufacturing, bottling, and shipping sulfur-containing herbicides, sulfur mustard, and Sarin. There is a need for analytical methods capable of determining these constituents quickly to determine exactly how specific waste structural materials should be handled, treated, and landfilled. These species are extracted rapidly from heated samples of soil or crushed concrete using acetonitrile at elevated pressure, then analyzed using a gas chromatograph equipped with a flame photometric detector. Thiodiglycol, the major hydrolysis product of sulfur mustard, must be converted to a silylated derivative prior to quantitation. Detection limits, calculated using two statistically-unbiased protocols, ranged between 2-13 $\mu \mathrm{g}$ analyte/g soil or concrete.
\end{abstract}

\section{INTRODUCTION}

Over the past fifty years, the facilities at Rocky Mountain Arsenal have been used for the manufacturing, bottling, and shipping of many chemicals, including rocket fuel, organochlorine pesticides, sulfur-containing herbicides, sulfur mustard, and Sarin. The Arsenal is presently remediating one hundred and eighty-one contaminated on-post sites as recommended by the recently-issued Record of Decision'. It is anticipated that the contaminants expected from the majority of these buildings or nearby soils will be identified using a knowledge of "previous usage." Such information will dictate the final method of disposal, normally either burial "in place" or in an on-site landfill.

The obvious difficulty is that not all areas may have a complete history of "previous usage," and that new analytical procedures will be necessary to quantitate target contaminants reliably both in soil and in unusual matrices such as crushed concrete. Such procedures should exhibit the following characteristics:

- They should provide results to the demolition crews rapidly, allowing relevant decisions to be made in a timely manner. The Laboratory Support Division of Rocky Mountain Arsenal presently demands that sample preparation be completed within an hour of sample delivery.

- They should exhibit reasonable selectivity towards the analytes of interest. 
- They should be able to accommodate limited sample masses.

- They should have detection limits which have been calculated using statistically-unbiased protocols. Note that regulatory standards have not been established for all of the contaminants; hence, the detection limit established by the analytical method will become the temporary regulatory limit.

- They should minimize the generation of hazardous chemical solvent waste.

Traditional extraction procedures for solid samples, such as Soxhlet or ultrasonic bath extraction, do not satisfy these criteria. The extraction times are frequently lengthy (overnight extraction is common); volatile analytes are frequently lost; the extraction of analytes from porous media such as concrete is often incomplete ${ }^{2,3}$; and large volumes of solvent waste are frequently generated.

Some recent analytical methods feature the rapid extraction of solid samples using small $(10-30 \mathrm{~mL})$ of solvent using elevated temperature and pressure. These procedures, which are frequently complete within $30 \mathrm{~min}$, often feature quantitative analyte recovery ${ }^{4,6}$. We report methods for the extraction of degradation products of sulfur mustard (1,4thioxane; 1,4-dithiane; thiodiglycol), organosulfur herbicides (4-chlorothioanisole and 4-chlorophenylmethyl sulfone), and small organophosphonates (dimethyl methylphosphonate, DMMP; di-isopropyl methylphosphonate, DIMP; diethyl ethylphosphonate, DEEP) from samples of soil and crushed concrete. The resulting extracts are analyzed using a gas chromatograph equipped with a flame photometric detector (FPD); the quantitations are performed using the method of internal standards. Thiodiglycol, a polar neutral species which is difficult to chromatograph reliably, is converted to a silyl ester prior to gas chromatography. Detection limits were established using Method Reporting Limit (U. S. Army) and Method Detection Limit (U. S. EPA) protocols, and range between 2-13 $\mu \mathrm{g}$ analyte/g soil or crushed concrete. Method turnaround time is approximately $1 \mathrm{hr}$ for all species except thiodiglycol, and $3 \mathrm{hr}$ for all analytes including thiodiglycol.

\section{MATERIALS AND METHODS}

\section{Chemicals}

Acetonitrile and methanol (HPLC grade) were purchased from J. T. Baker and used as received.

Sulfur-containing chemicals were purchased from the following vendors and used as received: 1,4-thioxane, syn. 1,4-oxathiane, CAS [15980-15-1], 98\% purity, Aldrich Chemical Co., Milwaukee, WI; 1,4-dithiane, CAS [505-29-3], 97\% purity, Aldrich; 1,3-dithiane, CAS [505-23-7], 97\% purity, Aldrich; 2,2'-thiodiethanol, syn. thiodiglycol or 2hydroxyethyl sulfide, CAS [111-48-8], 99+\% purity, Aldrich; 2-bromothioanisole, CAS [19614-16-5], 97\% purity, Aldrich; 4-chlorothioanisole, syn. 4-chlorophenyl methyl sulfide, 97\% purity, CAS [123-09-1], Lancaster Synthesis, Inc., Windham, NH; 4-chlorophenylmethyl sulfone, CAS [98-57-7], 98+\% purity, Lancaster.

Phosphorus-containing chemicals were purchased from the following vèndors and used as received: trimethylphosphate (TMP), CAS [512-56-1], 99+\% purity, Aldrich; triethylphosphate (TEP), CAS [78-40-0], 99+\% purity, Aldrich; dimethyl methylphosphonate (DMMP), CAS [756-79-6], 98\% purity, Johnson Matthey Catalog Co., Inc., Ward Hill, MA; di-isopropyl methylphosphonate (DIMP), CAS [1445-75-6], 98\% purity, Lancaster; dicthyl ethylphosphonate (DEEP), CAS [78-38-6], Pfaltz \& Bauer, Waterbury, CT. 
N-methyl-N-(t-butyldimethylsilyl) trifluoroacetamide (MTBSTFA) CAS [77377-52-7] with $1 \% t$ butyldimethyl-chlorosilane (TBDMS-Cl) catalyst CAS [18162-48-6], and silylation grade pyridine, CAS [110-86-1], were purchased from Pierce, Rockford, IL.

\section{Sample Preparation and Extraction}

Samples of crushed concrete or Rocky Mountain Arsenal standard soil (nominal mass $10 \mathrm{~g}$ ) were fortified for certification testing with known masses of test analytes. The surrogate compound for the analysis of organosulfurs was 4-bromothioanisole, while that for the analysis of the organophosphonates was triethylphosphate. The fortified samples were then extracted using a Dionex ASE 200 Accelerated Solvent Extractor (Sunnyvale, CA) with acetonitrile for $15 \mathrm{~min}$ at $100^{\circ} \mathrm{C}$ and $1500 \mathrm{psi}$. The resulting extract (nominal volume $25 \mathrm{~mL}$ per sample) was collected in precleaned $40 \mathrm{~mL}$ shell vials. Nominal sample-to-sample extraction time is $30 \mathrm{~min}$.

\section{Gas Chromatography}

A Varian Model 3400 gas chromatograph (Sunnyvale, CA) equipped with a septum-programmable injector (SPI), flame photometric detector (FPD, sulfur- or phosphorus-selective mode), and Varian Model $8200 \mathrm{CX}$ automatic sampler ( $5 \mu \mathrm{L}$ injections) were used for all determinations. The injector and detector temperatures were 200 and $220^{\circ} \mathrm{C}$, respectively. The gas flows for carrier gas (helium), nitrogen (make-up gas), hydrogen and air were set to factoryrecommended values.

Analyses of organosulfur species were performed using a $30 \mathrm{~m}$ x $0.53 \mathrm{~mm}$ i.d. fused silica column with Rtx()200 (Crossbond(B) trifluoropropylmethyl polysiloxane) bonded phase, $1.0 \mu \mathrm{m}$ film thickness, (Restek Corp., Bellefonte, PA) with matching deactivated fused silica guard column. The column oven temperature was programmed linearly as follows: $50^{\circ} \mathrm{C}$, hold for $5.00 \mathrm{~min}$; increase at $5.0^{\circ} \mathrm{C} / \mathrm{min}$ to $100^{\circ} \mathrm{C}$; increase at $2.5^{\circ} \mathrm{C} / \mathrm{min}$ to $115^{\circ} \mathrm{C}$; increase at $40.0^{\circ} \mathrm{C} / \mathrm{min}$ to $200^{\circ} \mathrm{C}$ and hold for $7.00 \mathrm{~min}$. Sample-to-sample analysis time is approximately $40 \mathrm{~min}$.

Analyses of the phosphorus-containing species were performed using a $30 \mathrm{~m} \times 0.53 \mathrm{~mm}$ i.d. fused silica column with Rtx $\otimes-200$ (Crossbond® trifluoropropylmethyl polysiloxane) bonded phase, $3.0 \mu \mathrm{m}$ film thickness, Restek Corp., with matching deactivated fused silica guard column. The column oven temperature was programmed linearly from $90^{\circ} \mathrm{C}$ to $150^{\circ} \mathrm{C}$ at $2^{\circ} \mathrm{C} / \mathrm{min}$. Sample-to-sample analysis time is also approximately $40 \mathrm{~min}$.

\section{Quantitation}

The total extract volume from the analysis of sulfur- or phosphorus-containing analytes was fortified with a known mass of 1,3-dithiane or trimethylphosphate, respectively, which served as internal standard. Quantitation was performed according to the method of internal standards.

\section{Derivatization of Thiodiglycol}

Underivatized thiodiglycol is not chromatographed reliably using the column parameters discussed, and must be derivatized prior to quantitation?. A $1 \mathrm{~mL}$ portion of acetonitrile was concentrated in the presence of $100 \mu \mathrm{L}$ silylation- grade pyridine to a final volume of approximately $100-200 \mu \mathrm{L}$. A $50 \mu \mathrm{L}$ aliquot of MTBSTFA with $1 \%$ TBDMS-Cl catalyst was added to the mixture, which was then heated for $1 \mathrm{hr}$ at $100^{\circ} \mathrm{C}^{8,9,10}$. The solution was allowed to cool, diluted to a final volume of $1 \mathrm{~mL}$ with fresh acetonitrile, and chromatographed as described. The quantitation 
of derivatized thiodiglycol was performed using the method of internal standards.

\section{Calculations}

The concentration of a given sulfur-containing analyte in either soil or concrete is given by

$$
\frac{m_{i s}}{w} * \frac{1}{K} * \sqrt{\frac{A_{a}}{A_{i s}}}=\frac{m_{a}}{w}=\text { Concentration of sulfur-containing analyte }
$$

s

where $\mathrm{m}_{\mathrm{a}}$ and $\mathrm{m}_{\mathrm{a}}$ are the masses of the internal standard and analyte, respectively; $\mathrm{w}$ is the mass of the soil or concrete sample; $\mathrm{A}_{\mathrm{is}}$ and $\mathrm{A}_{\mathrm{a}}$ are the integrated peak areas of the internal standard and analyte, respectively; and $\mathrm{K}$ is the slope of the calibration curve. (Note that the volume of the extract does not enter into the calculations at all.)

The concentration of a given phosphorus-containing analyte in either soil or concrete is given by

$$
\frac{m_{i s}}{w} * \frac{1}{K} * \frac{A_{a}}{A_{i s}}=\frac{m_{a}}{w}=\text { Concentration of phosphorus-containing analyte }
$$

\section{Certification Protocol and Calculation of Detection Limits}

The method evaluation was performed as detailed elsewhere ${ }^{11}$. Briefly, the certification was performed in two parts, and employed a desired "Target Reporting Limit (TRL)" of $5 \mu \mathrm{g}$ analyte/g soil or concrete. In the first part, two sets of seven soil or concrete samples fortified with analyte to 0.5 to 20 times the TRL were extracted and analyzed on consecutive days. The "found" concentration of each analyte, determined from the relevant calibration curve, was then plotted against the "true" concentration, determined from the known spike. These data and the resulting statistical confidence bands, were used to calculate the Method Reporting Limit (MRL), a statistically-unbiased detection limit value which permits the investigator to select levels of uncertainty for both false positives and false negatives (nominally $5 \%$ for each). The slope of the line representing the "found" vs "true" concentrations may be taken as an estimate for analyte recovery.

The second part of method certification involved calculation of the Method Detection Limit (MDL), as mandated in the Code of Federal Regulation ${ }^{12}$. Briefly, eight (minimum seven required) 1-L synthetic groundwater samples were fortified to $5 \times$ TRL and analyzed as described above. The standard deviation was then multiplied by the appropriate one-tailed Student's- $t$ statistic for $99 \%$ confidence. The resulting value is the MDL. 


\section{RESULTS AND DISCUSSION}

Table 1 summarizes the recovery, MRL, and MDL data for the organosulfur analytes in soil and concrete. The chromatograms from the "raw" acetonitrile extracts exhibited clean, sharp, symmetrical peaks which were baselineresolved for all components at concentrations ranging between $2-40 \mu \mathrm{g} / \mathrm{mL}$, with the exception of underivatized thiodiglycol. The latter compound frequently was not observed unless the concentration exceeded $10 \mu \mathrm{g} / \mathrm{mL}$. On the other hand, the MTBSTFA derivative of thiodiglycol, which eluted as a clean, sharp, symmetrical peak, between the surrogate 2-bromothioanisole and the analyte 4-chlorothioanisole, was easily observed between $1-40 \mu \mathrm{g} / \mathrm{mL}$.

TABLE 1

Summary of MRL, MDL, and Recovery Data for Five Sulfur-Containing Analytes in Soil and Concrete

\begin{tabular}{ccccc}
\hline Analyte & Matrix & Recovery, $\%$ & MRL, $\mu \mathrm{g} / \mathrm{g}$ & $\mathrm{MDL}, \mu \mathrm{g} / \mathrm{g}$ \\
\hline 1,4-Thioxane & Soil & 98 & 4.75 & 1.54 \\
& Concrete & 112 & $1.51 / 2.50^{2}$ & 2.16 \\
1,4-Dithiane & Soil & 99 & 2.50 & 1.62 \\
& Concrete & 101 & $0.89 / 2.50^{2}$ & 1.58 \\
Thiodiglycol & Soil & 87 & 13.39 & $12.63 / 10.48^{3}$ \\
& Concrete & $>100^{4}$ & 5.53 & $7.26 / 2.04^{3}$ \\
4-Chlorothioanisole & Soil & 103 & 4.05 & 2.06 \\
& Concrete & 99 & 4.32 & 1.70 \\
2-Bromothioanisole & Soil & 111 & Not calculated & 2.48 \\
& Concrete & 107 & Not calculated & 2.02 \\
4-Chlorophenyl & Soil & 102 & 3.91 & 2.06 \\
methylsulfone & & 99 & 3.73 & 2.02 \\
\hline
\end{tabular}

${ }^{1}$ Calculations use all eight available values unless noted otherwise.

${ }^{2}$ Calculated MRL is below the value of the lowest spiked sample tested, $2.50 \mu \mathrm{g} / \mathrm{g}$. Hence, $2.50 \mu \mathrm{g} / \mathrm{g}$ becomes the MRL.

${ }^{3}$ Uses the "best seven" values, i. e., the seven values with the smallest spread.

${ }^{4}$ Suspect recovery caused by loss of internal standard, as explained in text.

${ }_{5}^{5}$ Surrogate compound, not subjected to formal method certification. MDL only measured. Recovery estimated using the average of all eight concentration measurements. 
The calculated MRL or MDL value was typically smaller than the TRL of $5 \mu \mathrm{g} / \mathrm{g}$ for all analytes except thiodiglycol, and the method recovery typically exceeded $95 \%$. The somewhat greater MRL and MDL values for thiodiglycol, as well as a calculated recovery exceoding $100 \%$ for crushed concrete, probably reflect a loss of the internal standard 1,3-dithiane and/or thiodiglycol during the derivatization. These losses suggest that a different internal standard is required, possibly either 4-bromothioanisole (1,3-dithiane then becomes the surrogate compound) or 3,3'thiodipropanol?

Table 2 summarizes the recovery, MRL, and MDL data for the phosphorus-containing analytes in soil and concrete. Chromatography using the polar thick-film Rtx@-200 $0^{13}$ analytical column was essential for obtaining sharp, clean, symmetrical, baseline-resolved peaks for the analytes, internal standard, and surrogate. Satisfactory chromatography was not produced using columns employing either a thin-film (1 $\mu \mathrm{m})$ of Rtx(B-200 or more commonlyused phases (e. g., Stabilwax, DB-5, etc.) of thicknesses between 1-2 $\mu \mathrm{m}$.

TABLE 2

Summary of MRL and MDL Values for Phosphorus-Containing Analytes and Surrogate in Solid Matrices

\begin{tabular}{ccccc}
\hline Analyte & Matrix & Recovery, \% & MRL, $\mu \mathrm{g} / \mathrm{g}$ & MDL, $\mu \mathrm{g} / \mathrm{g}^{1}$ \\
\hline DMMP & Soil & 37 & 12.6 & $5.83 / 4.89^{2}$ \\
& Concrete & $65^{3} / 52^{4}$ & $37.43 / 9.11^{4}$ & $7.48 / 4.52^{2}$ \\
DIMP & Soil & 67 & 5.50 & $4.80 / 4.23^{2}$ \\
& Concrete & 94 & 3.12 & 1.22 \\
DEEP & Soil & 63 & 5.97 & $4.87 / 4.23^{2}$ \\
& Concrete & 90 & 3.30 & 1.49 \\
TEP & Soil & $82^{5}$ & Not calculated & $1.84 / 2.00^{2}$ \\
& Concrete & $86^{5}$ & Not calculated & 1.20 \\
\hline
\end{tabular}

${ }^{1}$ Calculations use all eight available values unless noted otherwise.

${ }^{2}$ Uses the "best seven" values, i. e., the seven values with the smallest spread.

${ }^{3}$ Uses the full data range, $0-116 \mu \mathrm{g} D M M P / g$ concrete.

${ }^{4}$ Uses a truncated data range, $0-58 \mu \mathrm{g} D M M P / g$ concrete.

${ }^{5}$ Surrogate compound, not subjected to formal method certification. MDL only measured. Recovery estimated using the average of all eight concentration measurements.

The MRL and MDL values were below the TRL for all analytes except DMMP, which exhibited erratic recoveries during method certification for both soil and concrete matrices. The reason(s) for this observation are not readily apparent, and may reflect thermal or surface-catalyzed degradation of DMMP during extraction which did not affect the other target species. It is also possible that the conditions were not entirely effective for the extraction of DMMP, although they were clearly effective for the other species and employed somewhat greater extraction pressures than similar methods. The recovery values from soil typically exceeded $60 \%$, while those from concrete were normally 
above $80 \%$.

These values suggest that the organophosphonates are clearly more difficult to extract from both matrices than the organosulfur species described previously, and that the former are extracted with less efficiency from soil than from crushed concrete. Such data suggest that soil samples are both more porous and more retentive than crushed concrete, as expected.

One goal of the initial method design was to employ both a common extraction procedure and a common set of gas chromatographic conditions. Such a plan assumed that the column effluent would pass through an FPD equipped with both sulfur- and phosphorus-selective "heads" and independent electrometers. Under these conditions, it would be possible to evaluate a single extract for sulfur- and phosphorus-containing analytes simultaneously. It became clear, however, that the thin film used to separate the sulfur-containing analytes would not be satisfactory for the organophosphonates. Further work will be needed to evaluate the elution behavior of the organosulfurs on the thick-film RtX®-200 column.

Another goal of the initial method design, namely rapid sample preparation and turnaround, was clearly satisfied. The sample extraction was normally completed within $30 \mathrm{~min}$, and the determination of all analytes except thiodiglycol could be completed in slightly more than one hour. Because a regulatory standard is not available at this time for the target species in soil and concrete, extreme sensitivity, requiring "heroic" efforts in the laboratory, was not required. The sensitivity of the method can be improved easily by using detectors such as the pulsed-flame photometric detector (PFPD), which can reduce the detection limit by as much as one hundred-fold for either organosulfur or organophosphorus species ${ }^{14}$. The existing selectivity from the FPD should permit the method to be employed successfully in the analysis of a variety of soils and building materials.

\section{CONCLUSIONS}

The above discussion demonstrates that Accelerated Solvent Extraction is an integral part of a successful analytical procedure for quantitating certain organosulfur and organophosphonate species in soils and building materials. The procedure is rapid (typical turnaround time approximately $1 \mathrm{hr}$ per sample) with a typical sensitivity of $5 \mu \mathrm{g}$ analyte/g soil or crushed concrete.

\section{ACKNOWLEDGMENTS}

Research sponsored by the Rocky Mountain Arsenal, DOE No. 1989-H077-Al, U.S. Department of Energy under contract DE-AC05-96OR22464 with Oak Ridge National Laboratory, managed by Lockheed Martin Energy Research Corp.

\section{REFERENCES}

1. "Record of Decision for the On-Post Operable Unit; Volume 1, Sections 1-11." Contract No. DAAA 85-92-D-0002. Denver, CO, Foster-Wheeler Environmental Corporation, March 1996. 
2. Watson, A. P., Kistner, S., Halbrook. R., Shugart, L., Buchanan, M. V., and Jenkins, R. A., "Technical Support for Recovery Phase Decision-Making in the Event of a Chemical Warfare Agent Release", in Sullivan, J. D., Wybo, J. L., and Buisson, L., eds., Proceedings of the International Emergency Management and Engineering Conference 1995, San Diego, CA, The Society for Computer Simulation, pp. 347-351.

3. Jenkins, R. A., Buchanan, M. V., Merriweather, R., Ilgner, R. H, Gayle, T. M., and Watson, A. P., J. of Hazardous Materials, 37, 303-325 (1994).

4. Method 3545, Accelerated Solvent Extraction, Revision 0, January 1995. Federal Register, 60, No. 142, Tuesday, July 25, 1995, pp. 37974-37980.

5. Richter, B., Ezzell, J., and Felix, D., "Single Laboratory Method Validation Report. Extraction of TCL/PPL (Target Compound List/Priority Pollutant List) BNAs and Pesticides Using Accelerated Solvent Extraction (ASE) with Analytical Validation by GC/MS and GC/ECD;" Document 116064.A, Dionex Corporation, June 16. 1994.

6. Richter, B., Ezzell, J., and Felix D., "Single Laboratory Method Validation Report. Extraction of TCL/PPL (Target Compound List/Priority Pollutant List) OPPs, Chlorinated Herbicides and PCBs Using Accelerated Solvent Extraction (ASE)." Document 101124, Dionex Corporation, December 2, 1994.

7. Assay Techniques for Detection of Exposure to Sulfur Mustard. Cholinesterase Inhibitors. Sarin, Soman, GF, and Cyanide. TB MED 296, Washington, D.C., Technical Bulletin Headquarters, Department of the Army, 22 May 1996.

8. Black, R. M., Clarke, R. J., Cooper, D. B., Read, R. W., and Utley, D., J. Chromatog., $\underline{637}$, 71-80 (1993).

9. Black, R. M., Clarke, B. J., Read, R. W., and Reid, M. T. J., J. Chromatogr. A., 662, 310 (1994).

10. Purdon, J. G., Pagotto, J. G., and Miller, R. K., J. Chromatogr., 475, 261 (1989).

11. Rocky Mountain Arsenal Chemical Ouality Assurance Plan. Version 1. Second Edition, Commerce City, CO, U. S. Army Materiel Command, April 1996.

12. Appendix B to Part 136 - Definition and Procedure for the Determination of the Method Detection Limit - Revision 1.11. Code of Federal Regulations: Protection of the Environment, Parts 100-149: Title 40: U. S. GPO: Washington, DC. Revised July 1, 1990.

13. “Rtxß-200: The Only Column of its Kind!" Restek Advantage Chromatography Newsletter, Fall, 1996.

14. S. Cheskis, E. Atar, and A. Amirav, Anal. Chem., 65, 539-555 (1993). 
M98000097

$$
\text { DoE }
$$

19971202083 